\title{
MALEBRANCHE: EL PLACER DINÁMICO Y ORDENADO
}

\section{MALEBRANCHE: DYNAMIC AND ORDERLY PLEASURE}

\author{
Alejandro José Pla Alfonso ${ }^{a^{*}}$
}

Fecha de recepción y aceptación: 30 de septiembre de 2020 y 7 de enero de 2021

DOI: https://doi.org/10.46583/scio_2021.20.722

Resumen: La crítica señala a Pierre Nicole como el pensador que hizo la transición entre aquellos primeros moralistas de mediados del siglo XVII que condenaban el mundo terrenal, y adoptaban una actitud negativa del ser humano, y los moralistas de la primera mitad del siglo XVIII, cuya visión moderna y mundana concebía al hombre bajo una perspectiva positiva. Este estudio pretende ubicar a Nicolas Malebranche como el otro pensador, quizá más en la sombra, quizá con un modo no tan explícito, que protagoniza dicha transición. Bajo el reinado de Luis XIV, el filósofo parisino, influenciado notablemente por San Agustín y Descartes, establece una psicología dinámica que le aleja del estático epicureísmo clásico y trasciende metafísicamente la moral cartesiana, dotándola de un sistema acabado en el que la figura de Dios ilumina el conocimiento y establece una moral bien definida. Su teoría del orden supone una puesta en valor del placer mundano, así como una congénita sociabilidad cristiana. Los acercamientos y alejamientos con Descartes

a Profesor de Filosofía en el Colegio Mas Camarena y doctorando en la Universitat de València.

${ }^{*}$ Correspondencia: Universitat de Valéncia. Facultat de Filosofia i Ciències de l'Educació. Avenida Blasco Ibáñez, 30. 46010 València. España.

E-mail: aplal@alumni.uv.es 
y la escolástica, así como sus interpretaciones de San Agustín, elucidarán en este estudio un prisma mundano de conceptos hasta la fecha de barniz cristiano. Toda moral y teoría del conocimiento parte en él de su metafísica cristiana.

Palabras clave: placer, moral, orden, Dios, amor, movimiento, concupiscencia.

Abstract: Criticism points to Pierre Nicole as the thinker who made the transition between those early moralists of the mid-17th century who condemned the underworld and adopted a negative attitude towards human beings, and the moralists of the first half of the 18th century, whose modern vision and worldly conceived man from a positive perspective. This study tries to place Nicolas Malebranche as the other thinker, perhaps more in the shadows, perhaps with a not so explicit way, who stars in this transition. Under the reign of Louis XIV, the Parisian philosopher, notably influenced by Saint Augustine and Descartes, established a dynamic psychology that distances him from the static classical Epicureanism and metaphysically transcends Cartesian morality, endowing it with a finished system in which the figure of God illuminates knowledge and establishes a well-defined morality. His theory of order supposes an enhancement of worldly pleasure, as well as a congenital Christian sociability. The approaches and distances with Descartes and scholasticism, as well as his interpretations of Saint Augustine, will elucidate in this study a worldly prism of concepts up to the date of Christian veneer. Every morality and theory of knowledge starts, in him, from his Christian metaphysics.

Keywords: pleasure, moral, order, God, love, movement, lust.

\section{$\S 1$. LOS INICIOS EN EL ORATORIO}

Quizá se antoje llamativo que las fechas de nacimiento y muerte de Nicolas Malebranche (París, 5 de agosto de 1638-París, 13 de octubre de 1715) resulten casi coincidentes con las de Luis XIV (Saint-Germain-en-Laye, Francia, 5 de septiembre de 1638-Versalles, Francia, 1 de septiembre de 1715). De la biografía del Rey Sol no parece complejo obtener información dada la entidad política del monarca francés. Del filósofo francés, no obstante, tampoco 
es muy complicado acceder a su recorrido vital y esto sucede gracias a los escritos del padre André, jesuita discípulo de Malebranche que redactó una biografía hoy considerada de referencia (Y. André. De la vie de R. P. Malebranche, prêtre de l'Oratoire, publicada en Francia por la editorial Poussièlgue en 1886). Miembro de una familia acomodada de París, su padre fue Nicolas Malebranche, tesorero del cardenal Richelieu y, en 1658, secretario del rey Luis XIII. Su madre, Catherine de Lauzon, originaria de Poitou (como la madre de Descartes), fue hermana de un virrey de Canadá y parienta de Madame Acarie. Mujer con una profunda formación religiosa, tendría influencia sin duda en la naturaleza reflexiva y recogida del futuro filósofo. Malebranche era el último de diez o trece hijos - "el último de diez hijos, dice el padre Adry, de trece, si creemos al padre André" (Joly, 1901: 12)-y mostró desde pequeño grandes dotes intelectuales en un cuerpo muy débil.

Debido a, precisamente, esta salud tan delicada, sus padres tomaron la decisión de que recibiera la educación elemental confinado en casa con un tutor privado. Tras estos primeros años preescolares, iniciaría lo que sería un breve paso por el colegio de La Marche, cerca de la plaza Maubert, no muy lejos del claustro Notre-Dame, donde vivían sus padres. Ahí estudiaría filosofía bajo la dirección de M. Rouillard, famoso peripatético, "pero que no conseguiría despertarle el interés por el peripatetismo... en decadencia" (Joly, 1901: 2). El 18 de junio de 1660 entra a formar parte, en condición de novicio, del Oratorio de San Felipe Neri, congregación reciente, pues había sido aprobada por Pablo IV en 1613. El cardenal de Bérulle fue su fundador y bajo su impulso los sacerdotes del oratorio cultivaban las ciencias del momento: matemáticas, historia, filosofía y ciencias sagradas. A diferencia de los jesuitas, más próximos a Aristóteles y a la doctrina experimental, el oratorio era más idealista y se aplicaba a buscar a Platón a través de San Agustín y por San Agustín. "El primer director de Malebranche cuando entró en el Oratorio fue Senault, autor de Del uso de las pasiones (1641) y El hombre de las pasiones (1648)" (Malinowski-Charles, 2012: 77).

Cuando el joven Malebranche entra en el Oratorio no deja una impresión demasiado positiva. Sus preceptores lo califican incluso de espíritu mediocre. Sin embargo, cuando se iniciaron las polémicas por sus pensamientos metafísicos "siempre halló respaldo entre los miembros de la orden" (D’Hautefeuille, 
1969: 472). En dicho lugar, situado en la calle Faubourg Saint-Honoré de París, pasaría la mayor parte de su vida, siendo uno de esos pensadores poco dados al cosmopolitismo. Ese 1660, además, fue el año en el que fallecen sus padres, con apenas diferencia de tiempo entre sí.

Tras la reglamentaria formación seminarista, en septiembre de 1664, recibe las órdenes sagradas y pasa a ser llamado abate Malebranche. Las lecturas de San Agustín se han convertido ya en un referente que no dejarán de acompañarle durante sus 77 años de vida. Pero al pensamiento de este Padre de la Iglesia se le sumará, ese mismo año de su ordenación como sacerdote, un descubrimiento que cobrará la misma trascendencia intelectual. Aunque los padres Gibieuf y De la Barde ya le habían comenzado a enseñar el cartesianismo, el momento clave se produciría con la lectura del Traité de l'homme de Descartes, que encontraría por azar en una librería del muelle de los Agustinos -otros dicen que la compra se produjo en la calle Saint-Jacques-. Pudiérase comparar este impacto entre filósofos con el que dos siglos más tarde tendría Schopenhauer sobre Nietzsche, cuando este último leyó El mundo como voluntad y representación. A partir de ese momento, el baile filosófico entre San Agustín y el padre del racionalismo será una constante en sus meditaciones. Veremos cómo el mecanicismo, el método matemático y el impulso metafísico se fusionan con el repliegue interno agustiniano de un modo brillante. Pero no compartirá sus líneas epistemológicas y morales.

Hasta la lectura de Descartes, su disciplina en el Oratorio discurría como la propia de los novicios, con la salvedad de que habiendo sido ordenado gozaba de una mayor libertad en la selección de los temas de estudio, de acuerdo con los principios de la congregación, en la que la intensa vida religiosa se conciliaba con los intereses culturales. Paralelamente, su biblioteca personal iría aumentando hasta componerse de "casi un millar de volúmenes", cuya parte principal lo formaban libros de filosofía y matemáticas: "Debíamos encontrar a Bacon y La Rochefoucauld, ya que los citaba. También a Montaigne, Balzar, Boileau y el Enfermo imaginario, además de poetas y oradores latinos. Malebranche no era tan enemigo como se ha dicho de la poesía y la literatura" (Joly, 1901: 51).

La formación del Oratorio descansaba en pilares tomistas y antijansenistas, fundamentalmente. De estos últimos conservará su línea de pensamiento, 
pero en sus escritos se percibe un distanciamiento del tomismo: "En sus escritos rechaza el tomismo y en general el método escolástico, así como las aportaciones medievales y los filósofos y moralistas del Renacimiento" (De Buzon, 2014: 1184) A uno de los grandes pensadores del Renacimiento, precisamente, dedicará todo un capítulo de De la recherche de la vérité: Montaigne. Así, todo el capítulo V de la III parte de libro II lo centra en el autor de los Ensayos. Afirma ahí que el "placer" de los escritos de Montaigne emana de su "concupiscencia", pues no hace sino "entretener y fortificar las pasiones" (Malebranche, 1842: 203). Más adelante lo llama "pedante de espíritu mediocre": "Los pedantes no pueden razonar dado que tienen un espíritu pequeño o, más bien lleno de falsas erudiciones [...] el libro de Montaigne contiene pruebas tan evidentes de la vanidad y el orgullo de su autor" (Malebranche, 1842: 204). Tampoco duda en señalarle como autor de pecados capitales. Tanto por el uso del término teologal concupiscencia, como por las acusaciones de orgullo y vanidad. Lo compara a un demonio y no vacila en citar el Apocalipsis para referirse a él: "Solo los demonios y los que participan del orgullo de los demonios se jactan de ser adorados [...] hay muy pocos capítulos en los que no haga una digresión para hablar de sí mismo, e incluso hay capítulos enteros donde solo habla de él" (Malebranche, 1842: 204-205). Finalmente, le reprocha su escepticismo por ser una moda -"era necesario en su época, a fin de parecer hábil y galante, dudar de todo"- con respecto a la metafísica. También le tilda de "confundir el espíritu con la materia" y de no ver la "necesidad de la inmortalidad del alma al afirmar que la razón humana no pudiera reconocerla" (Malebranche, 1842: 209). Esos años iniciales de estudios en lenguas orientales y patrística fueron reemplazándose por un profundo estudio de la obra cartesiana. Debieron pasar diez años hasta el primer volumen de Recherche de la vérité. El segundo llegaría al año siguiente, en 1675, seguido de un tercero de Éclaircissements (1678). Malebranche no dejará de hacer correcciones sobre estos escritos, que conocerán distintas ediciones aumentadas y revisadas por el propio autor. En 1677 publica Conversations chrétiennes, a petición del duque de Chevreuse, y que edita a modo de resumen de su sistema de pensamiento.

Ese mismo año saldría a la venta Petites méditations sur l'humanité et la pénitence, que le valdría un fuerte enfrentamiento con Arnauld, autor al que 
se dedicará un capítulo más adelante. Malebranche se retractará en 1697 publicando Traité de l'amour de Dieu, obra que apacigua los ánimos con Port Royal y que le reconcilia con Bossuet en el quietismo. Un año antes, sin embargo, había redactado y publicado Entretiens sur la mort (1696), que gira en torno a las conversaciones e ideas sobre la muerte de tres hombres: uno piensa que la vida es demasiado corta, otro que es demasiado larga y el último, más espiritual y consciente sobre las experiencias que ha tenido, plantea que la muerte solo expande nuestras mentes ${ }^{1}$.

Dos años después fue nombrado miembro honorario de la Academia Francesa de las Ciencias por sus aportes en las matemáticas, así como miembro honorario del ya célebre Oratorium Iesu, fundado por Pierre de Bérulle en París. En sus últimos años de vida publica Entretien entre un philosophe chrétien et un philosophe chinois (1708) y Réflexions sur la prémonition physique, en respuesta al libro de Boursier L'action de Dieu sur les créatures ou De la prémonition physique, aparecido en 1713. Malebranche muere el 13 de octubre de 1715 en el Oratorio.

\section{§2. San Agustín y La CONDENa de los Sentidos}

No hay duda de que la religiosidad de su madre y sus años como seminarista en el Oratorio depositaron en él una influencia notable en lo que respecta a las lecturas de San Agustín. Los textos de este Padre de la Iglesia y la condena del mundo terrenal jalonarán la obra del filósofo francés. El mundo terrenal, el cuerpo y los sentidos dificultan al ser humano poder escuchar el Verbo divino. La palabra de Dios, condición epistemológica por un lado, y principio moral por otro, debe llegar al hombre con claridad. Dios nos habla en voz baja, por lo que debemos minimizar el ruido. Este movimiento interior, esa reclusión vital en pos de la gracia que nos enseñe qué es el verdadero bien, que nos posibilite ocasionalmente el acceso epistemológico a la verdad, requiere de un desprendimiento terrenal, de un alejamiento del otro que no hace sino introducir dificultades a la hora de escuchar el Verbo. "Como para

\footnotetext{
${ }^{1}$ Si no se indica lo contrario, las traducciones de los textos son propias.
} 
San Agustín, la razón habla a todo el mundo de manera idéntica, pero en voz baja: reestablecernos en el orden será pues dar la palabra a la Razón universal o Verbo divino" (Canto-Sperber, 2014: 1184). En su Traité de morale afirma que hay que hacer "grandes esfuerzos" por escuchar la verdad "cuando nuestros sentidos están estimulados" (Malebranche, 1995: 108). Y unas páginas más adelante, en el capítulo $\mathrm{V}$ del apartado que dedica a la virtud, lo establece ya de un modo que no arroja duda alguna sobre su intención:

[...] facilitar la meditación. Solo el cuerpo entorpece el espíritu: he aquí el principio de nuestra estupidez. Sin embargo, todos los objetos terrenales actúan en nosotros mediante nuestro cuerpo. Así pues, vemos claramente que se trata de acallar los sentidos, la imaginación y las pasiones, en una palabra, el ruido confuso que el cuerpo excita en nosotros, para poder escuchar sin pena las respuestas de la Verdad interior (Malebranche, 1995: 110).

Este repliegue interior, este abandono del mundo terrenal, confuso y corrupto, rezuma a la Ciudad de Dios de San Agustín y, por supuesto, a Platón. Debemos, pues, ejercitar una vida que acalle todo ese ruido fruto del mundo terrenal. Los sentidos, la imaginación y las pasiones no hacen sino dificultar el tránsito del ser humano hasta Dios. De todos los ejercicios que favorecen la eficacia de la gracia divina no hay otro más necesario que la mortificación de los sentidos: "Así, aquel que mortifica los sentidos combate en su principio la unión del espíritu al cuerpo, o más bien, su dependencia. Disminuye su vida animal, el peso del pecado, la concupiscencia y favorece la eficacia de la gracia" (Malebranche, 1995: 181). De hecho, en el capítulo XIII dedicado a la virtud definirá las pasiones como "ese movimiento del alma y del espíritu causado por los sentidos y la imaginación" (Malebranche, 1995: 200). El cuerpo como fuente "corruptora" del espíritu y del corazón de los hombres:

El cuerpo no habla al espíritu más que para cegarlo y lo corrompe a su favor. Dios a través de la luz conduce el espíritu hacia su felicidad: el cuerpo mediante el placer arroja al hombre a la desgracia [...] podemos decir que es el cuerpo el que ciega el espíritu y corrompe los corazones: ya que es la unión del espíritu al cuerpo la causa de todos los errores y de todos los desórdenes del hombre (Malebranche, 1995: 168). 
En la segunda parte del libro II de De la recherche de la vérité, al amparo de una suerte de base fisiológica sobre la distintas "fibras" que los seres humanos tenemos en el cerebro -y que varían según sexos y edades-, apunta a las mujeres como el sexo más proclive a vivir atado al mundo sensible; en consecuencia, con mayores dificultades para escuchar el Verbo divino. El capítulo I de esta parte II, que versa sobre la imaginación, sirve a Malebranche para realizar esta suerte de estudio biológico al más puro estilo de Descartes en Les passions de l'âme. En torno a la imaginación de las mujeres comienza diciendo así:

Esta delicadeza de las fibras que de ordinario se halla en las mujeres, y es lo que les otorga esa gran inteligencia para todo aquello que afecta a los sentidos. Corresponde a las mujeres decidir sobre la moda, juzgar las lenguas, distinguir entre las buenas y malas maneras. Tienen más ciencia de habilidad y finura que los hombres sobre este tipo de cosas. Todo aquello que dependa del gusto les atañe, pero de normal son incapaces de penetrar en las verdades de difícil acceso. Todo aquello que es abstracto les resulta incomprensible $[\ldots]$ no consideran más que la superficie de las cosas (Malebranche, 1842: 142).

Malebranche suaviza lo que sin duda parece una actitud misógina característica de la época, y quizá por la fuerte influencia de la escolástica en el continente, apuntando que a toda regla "le corresponden sus excepciones". Así matiza que hay mujeres fuertes y constantes del mismo modo que existen hombres débiles e inconsistentes: "Hay mujeres sabias y valientes, capaces de todo; y por el contrario hay hombres blandos y feminizados, incapaces de penetrar en nada y de no llevar nada a cabo" (Malebranche, 1842: 142). Pese al matiz, no deja de reconocer que "la mayoría de las mujeres y algunos hombres" tiene esas fibras extremadamente delicadas durante toda su vida. Parece, pues, que el varón se distrae menos con el mundo sensible y emerge como más capacitado para trascender el mundo terrenal corrupto y escuchar así el Verbo divino. Pero ¿cualquier varón y a cualquier edad? A este respecto, Malebranche señala una franja de años en el varón adecuada para ello: de los treinta hasta los cincuenta. Antes se es demasiado joven y las fibras aún son "débiles y delicadas", y a partir del medio siglo de vida se han endurecido demasiado provocando que el hombre caiga en la vanidad y en la presunción 
de conocimiento y juicio seguro: “La mayor perfección del espíritu es a partir de los treinta años y hasta los cincuenta. Los placeres y dolores de los sentidos no tienen tanto efecto [...] las pasiones actúan rara vez en él [..] así el alma al no ser entretenida por las cosas sensibles puede fácilmente contemplar la verdad" (Malebranche, 1842: 143).

\section{§3. CONCUPISCENCIA O EL MOVIMIENTO DETENIDO}

El placer que permanece anclado al mundo terrenal posee un término bien definido en el cristianismo: concupiscencia. Cyril Morana lo define así en su glosario del análisis que realiza a las partes II y III de De la recherche de la vérité: "Designa el deseo desordenado e insaciable de una voluntad corrompida por el pecado. Debido al pecado original, todos los hombres nacen pecadores y concupiscentes. Tiene, por ello, sus almas subordinadas al cuerpo" (Morana, 2006: 150). Malebranche ahonda en este concepto derivado de las lecturas de San Agustín y de la propia Biblia que más adelante veremos, pues no duda en aludir continuamente a las Santas Escrituras a lo largo de su obra, preferentemente en latín, lengua culta aún en Francia y en el resto de Europa. "Mientras que el buen amor está unido al conocimiento, el mal amor lo está a las sensaciones o a las pasiones, ambas, instrumentos de la concupiscencia" (De Buzon, 2014: 1186). La concupiscencia, pues, aleja al espíritu de la verdad. En el segundo volumen del Dictionnaire d'éthique et de philosophie morale, dirigido por Monique Canto-Sperber, en la voz dedicada al filósofo francés, escrita por Frédéric de Buzon, se explica ampliamente el pensamiento de Malebranche con relación a este término:

La manifestación de la concupiscencia es el amor de los falsos bienes, es decir, cuando la voluntad se detiene en ciertos bienes, cuando aún le queda al hombre movimiento para ir más allá hasta el bien infinito e indeterminado, y se entiende en el actual desorden, es decir, tras ese lapso. Supone una explicación metafísica y física del orden y de su opuesto (De Buzon, 2014: 1186).

Conviene señalar, no obstante, que el filósofo francés no restringe la concupiscencia a esa imagen pecaminosa del mundo carnal que el cristiano tiene 
en mente, sino que insiste en ampliarla al sentimiento de orgullo, que supone un lastre en el ser humano a la hora de elevarse hacia la verdad: "El hombre está sujeto a dos tipos de concupiscencia, la concupiscencia de los placeres, y la concupiscencia de la elevación y el orgullo" (Malebranche, 1995: 198). Antes de finalizar ese mismo capítulo lo termina de clarificar así:

Todos los hombres reconocen con cierta facilidad el desarreglo que produce la concupiscencia carnal. Desconfían de ella, la temen, evitan las situaciones que pueden provocarla. Pero pocos hay que hagan una seria reflexión en torno a la concupiscencia del orgullo y que corren el riesgo de aumentarla. Discretamente todos se abandonan el comercio mundano, embarcándose sin miedo en esas aguas tormentosas, como las llamaba San Agustín. Se aspira a la grandeza, se corre en pos de la gloria [...] al final uno se hace un nombre, pero un nombre que le hace más esclavo de lo que ha sido para merecer dicho nombre: un nombre que nos ancla a las criaturas y nos aleja del Creador (Malebranche, 1995: 199).

Malebranche evidencia la inquina con la que buena parte del mundo cristiano miraba al pueblo judío. Esto se evidencia en las acusaciones abiertas hacia ellos al señalarlos, precisamente, como pueblo dado a dicha concupiscencia: "Este pueblo era muy dado a los placeres groseros y carnales, siempre entregados a la idolatría, en la que recaían continuamente [...] las amenazas de los bienes y males terrenales, que eran el objeto de su concupiscencia" (Malebranche, 1995: 164). Para el filósofo parisino, en definitiva, el "error proviene de la injerencia de los sentidos que tienen su raíz en el pecado original. Se vence el oscurecimiento del alma en la unión con Dios" (Garmendia de Camusso, 2004: 27). Antes del pecado original, Adán detenía los movimientos que excitaban su cuerpo por los cuales su alma sentía placer y dolor. Conservaba de ese modo una capacidad de pensar virgen y libre de amar a Dios: "Era por tanto por decisión y por razón (y no por instinto) que amaba Dios. Tras el pecado original la unión de alma y cuerpo se tornó dependiente. El amor y el conocimiento de Dios son hoy, si no ausentes, difíciles de lograr. El placer hoy es lo que nos desvía de Dios" (Geny, 2015: 494). Así pues, para Malebranche la concupiscencia se tornó desde entonces como pérdida de poder en el ser humano. 
Finalmente, sabemos por el cartesianismo y toda su mecánica del movimiento que este permanece constante en los cuerpos. Aquello que varía es la dirección. Una mala dirección o una interrupción son síntomas de concupiscencia. Del mismo modo, para Malebranche sucede con la fuerza que reside en el alma, cuya fuerza es la misma, solo que corre el riesgo de desviarse o dispersarse si no escucha la palabra de Dios:

No sigue, en línea recta, el movimiento inicial al que debería ceder. Cuando se desvía o, sobre todo, se detiene en un bien particular, siente que posee recorrido para ir aún más lejos. Va, pues, de objeto en objeto, viendo confusamente algún bien en unos y otros; pero ninguno de esos bienes incompletos es capaz de satisfacerle. Tras desviarse o detenerse en uno u otros, retoma enseguida su inquietud. Nada hay que pueda detener el movimiento del alma que Aquel que se lo ha impreso (Joly, 1901: 11).

\section{§4. No ELIMINAR EL CUERPO: MANTENERLO}

Tras esta dura crítica a los sentidos, a la imaginación y las pasiones, en definitiva, a la concupiscencia del ser humano, resulta tentador pensar que acabar con el cuerpo resolvería el problema: "Si tu ojo te es ocasión de pecar, arráncatelo y échalo de ti" (Mateo 18.9). Es decir, si la parte corporal del hombre es aquello que le mantiene atado al mundo terrenal, engañoso y fuente de obstáculos para su comunicación con Dios, ¿por qué no erradicar la vida terrenal? El propio Malebranche lanza esa hipótesis que enseguida se apresura a neutralizar. El capítulo XI dedicado a las virtudes de su Traité de morale lo inicia explicando "qué tipo de muerte" se debe tener para ver a Dios y escapar de la concupiscencia. Malebranche rehúye del estoicismo y de las corrientes extremas del epicureísmo (ciertos sectores cirenaicos) que invitan al suicidio. El quinto mandamiento afirma rotundamente "No matarás". Pero del mismo modo que en De la recherche de la vérité explica que las fibras del cerebro son distintas y pueden habituarse para sentir el Verbo divino, también aquí desea sistematizar qué tipo de mortificación corporal es la adecuada para que el espíritu del hombre vea a Dios. Y así, al inicio de dicho capítulo, afirma que la muerte es un camino breve para desquitarse de la concupiscencia 
y romper de golpe esta "unión desgraciada" que nos impide reunirnos con Dios. No obstante, en la siguiente frase recuerda que no es necesario probar que quitarse la vida es un "crimen" que lejos de unirnos con Dios nos aleja de Él "para siempre": "Está permitido despreciar la vida e incluso aspirar a la muerte, como decía San Pablo: Desidirium habens dissolvi et esse cum Christo. Pero estamos obligados a conservar la salud y la vida. Ha de ser la Gracia la que nos salve de la concupiscencia" (Malebranche, 1995: 177).

Queda claro, pues, que Malebranche ni defiende ni insinúa llevar a cabo actos que tiendan al suicidio. Se trata, por un lado, de mantener el cuerpo sano y con vida, y por otro prestar atención al Verbo divino para que sea Este quien nos libre de la concupiscencia: "Morimos en el cuerpo y en el mundo en la misma proporción que entramos en nosotros mismos, que consultamos la verdad interior, que nos unimos y obedecemos la Orden" (Malebranche, 1995: 178). Y por si había alguna duda, algunas líneas más adelante lo redondea así: "Se debe conocer y amar a Dios desde esta vida para poseerlo en la otra".

No hay que darse la muerte que mata el cuerpo y acaba con la vida, mas se debe dar la muerte que fatiga el cuerpo y disminuye la vida; yo entiendo la unión del espíritu al cuerpo o su dependencia respecto a él. Se debe comenzar y continuar este sacrificio y esperar de Dios la consumación y la recompensa, pues la vida del cristiano en la Tierra es un sacrificio continuo durante el cual inmola constantemente su cuerpo, su concupiscencia y su amor propio en pos del amor al Orden (Malebranche, 1995: 178-179).

Si la imaginación y los sentidos no son fuente de verdad, no son condición epistemológica, ni tampoco precepto moral, ¿qué objeto tienen? Su función es la de procurar la conservación del cuerpo humano. Algo puramente biológico y animal. Sin más. Pero la gran aportación de Malebranche descansa en ser capaz de ver que los movimientos del cuerpo en busca de los placeres terrenales forman parte de un mismo movimiento que, más trascendente, aspira a Dios. Esto nos trae ecos de El Banquete de Platón y del ascenso desde la belleza múltiple en los cuerpos físicos hasta el concepto de belleza y finalmente la idea de Bien -que corona todas las ideas en el sistema ontoepistemológico platónico-. Reconoce, pues, un valor, aunque menor, a los placeres terrenales. $\mathrm{Da}$ autoridad al placer mundano, aunque sea con rango de preámbulo hasta 
la visión de Dios. Y esta afirmación, además de suponerle un fuerte conflicto con Port Royal, el jansenismo y el padre Arnauld, que analizaremos más adelante, lo coloca como pionero en la rehabilitación del concepto de placer.

A partir de 1680 se busca un terreno de entendimiento que permita fusionar un sistema de explicación único al hombre de la naturaleza con el hombre de la Gracia divina. Malebranche fue el primero en darse cuenta de que los motivos que impulsan al corazón humano son siempre los mismos, y que un mismo movimiento le conduce hacia los bienes eternos y hacia la felicidad ilusoria (Mauzi, 1994: 180).

Esta conexión entre el cuerpo y el alma posee claras influencias cartesianas. Ya había hablado Descartes en su primera parte de Les passions de l'âme de esa glándula pineal como punto de encuentro a través de la cual alma y cuerpo se comunican: "El alma se ubica en una pequeña glándula que se encuentra en mitad del cerebro, desde donde irradia al resto del cuerpo a través de los espíritus, nervios y de la misma sangre" (Descartes, 1996: 121). Syliane Malinowski-Charles señala que Descartes no duda en reconocer que las pasiones "nos son dadas por Dios para un bien esencial, a saber, la preservación de nuestro cuerpo" (Malinowski-Charles, 2012: 68). Y así lo explicaba Descartes en el artículo 137 de la segunda parte de Les passions de l'âme:

Según la institución de la naturaleza, las pasiones tienen que ver con el cuerpo, y no se dan en el alma sino porque está unida a él; de tal modo que su uso natural es incitar al alma a consentir y atribuir a las acciones que pueden servir a conservar el cuerpo o hacerlo en cierto modo más perfecto. $\mathrm{Y}$ en este sentido la tristeza y la alegría son las dos primeras que son empleadas (Descartes, 1996: 182).

Hemos visto antes de qué modo Malebranche pone en valor los placeres mundanos al considerar que forman parte del mismo impulso - élan- que conduce el espíritu humano a su encuentro con Dios. "El alma se ata por un tiempo a los valores mundanos y a los bienes perecederos, va de experiencia en experiencia [...] sueña con un placer sin malestar y del que no despierte para elevarse lentamente de la ilusión hasta la verdad" (Mauzi, 1994: 18). Es un movimiento unidireccional que se nutre en todo momento del propio deseo. 
Además, se trata de un ascenso sin pausa ni socavones. Un impulso dinámico del alma. Este dinamismo sin interrupciones aleja a Malebranche, por otro lado, del epicureísmo clásico, de los valores estáticos del Jardín.

En ningún momento el placer exige una conversión brutal ni renuncia abrupta. De los prestigios mundanos a la iluminación final, de la inquietud natural al reposo sobrenatural, no se produce un tránsito brusco, sino una elevación continua [...] el epicureísmo enseña a mantener el alma en equilibrio, alejada de las pasiones. La psicología dinámica de Malebranche puede justificar perfectamente el movimiento como principio de vida interior (Mauzi, 1994: 18).

Para acabar este capítulo, como afirma Jean-Christophe Bardout, la reflexión de Malebranche evoluciona y le conduce a redefinir la voluntad humana como "deseo de ser feliz" y no simplemente como tendencia indeterminada y general al bien: "Esto le lleva a repensar el fundamento de los actos voluntarios, dotando al placer de un lugar preponderante" (Bardout, 2005: 98). Por si acaso, convendría dejar claro que pese a que la rehabilitación de la doctrina hedonista fue intensa desde 1660 y hasta el siglo siguiente incluido -como lo atestiguan Du Rondel (La moral de Epicuro) y Gassendi (Ethica Epicuri), entre otros-, Malebranche critica en De la recherche de la vérité y en su obra en general a los epicúreos, tanto a los antiguos como a los modernos, y por ello "no es sospechoso de pertenecer al clan de los Gassendi, Saint-Évremond y otros" (Solère, 1995: 354).

\section{§5. Bossuet y Arnauld: DeSEncuentros}

Comentábamos al principio de este estudio que la formación de sus años en la Congregación del Oratorio de San Felipe Neri descansaba en pilares tomistas y antijansenistas. En 1664 fue nombrado sacerdote durante un seminario que había arrancado en 1660 y que ya en 1661 había producido el primer desencuentro público con las prácticas de Jansenio, inspirador del pensamiento de rigor y retiro de Port Royal. Desde abril hasta octubre de aquel 1661 lleva a cabo estudios de teología en Saumur. A su vuelta a París se centraría 
en el estudio del hebreo y de la historia eclesiástica, junto a su compañero de seminario Richard Simon. Firmaría un formulario antijansenista del que deberá retractarse en 1673 tras la lectura del Augustinus. El desencuentro comenzaba a avivarse.

En 1680 Malebranche publicaba su Traité de la nature et de la grâce. Un año más tarde mantiene relación con Bossuet, quien comenzaría a criticar su pensamiento ya en 1683 (sin nombrarlo) en la Oración fúnebre de María Teresa de Austria. A lo largo de aquel año los distanciamientos y las críticas por parte de los defensores de Port Royal se agudizan. Malebranche acababa de publicar sus Méditations chrétiennes, obra a la que respondería Arnauld, que como todos sus amigos de Port Royal era cartesiano (y estos eran combatidos por los jesuitas), con Des vraies et des fausses idées, contre ce qu'enseigne l'auteur 'De la Recherche de la vérité'. Este libro marcaría el inicio de una larga polémica con Malebranche que se extenderá hasta 1694, fecha de la muerte del padre Arnauld. En 1690 su Traité de la nature et de la grâce es puesto en el Índice. Siete años más tarde se ve implicado por el benedictino François Lamy en la querella de Puro Amor y redacta el Traité de l'amour de Dieu, que le ocasiona su ruptura con Lamy y le aproxima a Bossuet, del que se había distanciado. En 1709 su obra De la recherche de la vérité es incluida también en el Índice y en 1714 su Traité de morale.

"Que el jansenismo fuera combatido abiertamente, como lo era, en el nombre de la filosofía y en el nombre del dogma, y todo ello por un cartesiano, he ahí sobre todo lo que Port Royal no podía aguantar sin enfado creciente. Es bien cierto que ahí se halla el origen y todos los ataques apasionados de Arnauld" (Joly, 1901: 31). Los desencuentros con los partidarios de Jansenio $\mathrm{y}$, por extensión, con aquellos defensores de una moral cristiana rígida que proscribiera los placeres mundanos y el mundo terrenal en general, comenzaron pues ya en el Oratorio y no cesaron hasta la muerte de Malebranche. No obstante, si debiéramos situar la fase más virulenta habría que viajar hasta mediados de la década de 1680 como punto de partida del inicio de la querella entre Malebranche, Arnauld y Bayle.

Con motivo de la publicación del Traité de la nature et de la grâce, Arnauld percibe en dicha obra una rehabilitación de los placeres, que en el libro de Malebranche aparecen espiritualizados, como viniendo de Dios, que 
los desliza en nuestra alma con "ocasión" de las percepciones sensibles. A partir de ese instante, la felicidad terrestre, los placeres mundanos, no hacen sino las veces de heraldo de los placeres espirituales que están por venir, pero siempre, como ya hemos explicado, formando parte de la misma inercia, del mismo élan. Este punto de vista lo comparten, entre otros, Robert Mauzi:

No existe discontinuidad de cara a los placeres eternos. La Gracia y la Naturaleza dejan de oponerse, colaborando armoniosamente en la felicidad del hombre. Contra tal herejía Arnauld se rebela, y desea mantener el distanciamiento entre Gracia y Naturaleza. Y recuerda que ningún placer atado a la condición terrestre puede calificarse de 'bien' y que nuestra felicidad no se halla en este mundo (Mauzi, 1994: 182).

Malebranche no distingue como Descartes la voluntad del sentimiento o del afecto, lo identifica con dicha tendencia hacia el placer y la felicidad en la propia naturaleza creada por Dios: "Esta tendencia es un impulso dado por Dios y debe regresar a Él; pero si Dios es el fin, la búsqueda de la felicidad es el motivo [...] el deseo de felicidad es el único motivo de todos nuestros motivos, el «amor de nuestros amores»" (Solère, 1995: 356)".

La publicación del Traité de la nature et de la grâce fue como una granada teológica cuya metralla alcanzó mucho más allá de Port Royal. Si los jansenistas no estaban nada satisfechos de la exposición tan novedosa y audaz de esta obra, los tomistas tampoco, y los molinistas mucho menos: "Los unos entendían que daba demasiado protagonismo a la naturaleza y a la libertad, los otros que no le concedía suficiente. Bossuet, que no era jansenista, pero que sí era cartesano en filosofía, era tomista en teología, se molestó, con más de una tesis del libro" (Joly, 1901: 31). Recordemos que se distingue tradicionalmente al jansenismo, donde la gracia actual (necesaria para comportarse adecuadamente y obtener la salvación) es eficaz por sí misma, del molinismo, que por el contrario defiende la existencia de una gracia suficiente que empuja a hacer el bien pero que logra su efecto mediante el consentimiento y cooperación del hombre. Por no olvidar las tesis de Pelagio, que estipulan la posibilidad en el hombre de bien de actuar y merecer así la salvación por su propio esfuerzo. $\mathrm{O}$ incluso el semipelagismo, que establece que el hombre 
puede comenzar por sí mismo su mejora, pero solo puede completarla con el concurso de la gracia divina.

Habíamos hecho mención a Bayle en la querella. Y es que el pensador de Ariège, considerado -junto a Fontenelle- la figura de la primera Ilustración francesa, demuestra que la felicidad verdadera proviene del mundo terrenal, pues así lo ha querido Dios, quien concibió al hombre para ello; pero que ese mismo Dios, de una manera sutilmente retorcida, "nos prohíbe por la Revelación gozar de las ventajas de las que nos ha dotado la naturaleza" (Mauzi, 1994: 182). Frédéric de Buzon coincide también en que una de las tesis "más controvertidas" de la filosofía moral de Malebranche tiene que ver con la realidad y la bondad del placer. Reproduce algunos de los pasajes que desencadena la polémica con Arnauld para justificarla:

"Todo placer es un bien y torna feliz al que lo goza en el instante que lo goza y tanto como lo hace" o bien "El placer es el carácter del bien" (en Recherche de la vérité IV, X y en Réponse à la dissertation de M. Arnauld VIII, respectivamente). Se entiende pues, evidentemente, la acusación de epicureísmo o de hedonismo llevada a cabo por P. S. Régis y A. Arnauld (De Buzon, 2014: 1188).

No debemos olvidar tampoco su relación de encuentros y desencuentros con Bossuet. Relation sur le quiétisme, publicada en 1698 por JacquesBénigne Bossuet, supuso un posicionamiento claro contra el quietismo o molinosismo (doctrina del jesuita español Miguel de Molinos, que no hay que confundir con el teólogo Luis de Molina, y que establecía que el alma, en la contemplación de Dios, llegaba a una "quietud" absoluta), y contra su principal defensor en Francia, Fénelon. Hay que recordar que Bossuet, con su áspera y tenaz polémica, consiguió que la curia romana condenara la obra de Fénelon (1699). Malebranche toma partido del lado del obispo de Meaux, dado que para el filósofo el placer es al mismo tiempo el sello del bien y el único motivo de nuestras acciones: “Así pues, en las polémicas relativas al quietismo, Malebranche se pone del lado de Bossuet contra la doctrina del Puro Amor de Fénelon. El placer constituye el motivo físico de toda acción, impreso en el hombre por Dios para dirigirlo hacia su fin" (De Buzon, 2014: 1188). 
La querella del Puro Amor oponía algunos quietistas, como Guyon o Fénelon, a otros filósofos o teólogos, como Malebranche o Leibniz. Dicha querella descansaba en saber si el hombre era capaz (o no) de un amor de Dios que fuera totalmente desinteresado y que constituyera en cierto modo la recíproca de la perfecta gratuidad del amor divino por el hombre. Para Malebranche Dios no sabría ser amado de manera desinteresada. En su Explicación sobre las máximas de los santos, Fénelon había definido diversos tipos de amor de Dios, siendo el último de ellos -el quinto, que establece que debemos amarle no por el mérito, ni por la perfección ni la felicidad, incluso ignorando él que le amamos- el que Lamy veía como la única forma de amor verdaderamente digno de Dios: "Para Fénelon el amor hacia Dios no solo debe ser totalmente desinteresado, sino que el alma que ama a Dios debe ser absolutamente indiferente a su propia salvación [...] esta concepción del amor divino es muy peligrosa para las instituciones eclesiásticas, ya que deja de hacer necesaria toda mediación entre los viatores y Dios" (Priarolo, 2015: 153).

Esta huella impresa en el hombre recuerda, sin duda, al argumento de San Agustín que René Descartes retomará como uno de sus argumentos demostrativos de la existencia de Dios a la hora de apuntalar su segunda certeza: la sustancia infinita o res infinita. Y es que el pensamiento de Malebranche orbita alrededor de San Agustín. El prólogo del Evangelio según San Juan era el lugar común para las reflexiones tanto del Padre de la Iglesia como del propio Malebranche; en este se refleja que el alma humana da testimonio de la luz divina, pero no es la propia luz divina. "Fénelon reprocha a quienes hacen depender la voluntad divina a un orden necesario y eterno. En este aspecto, Malebranche mantuvo una posición audaz y sabia entre la postura de Descartes y aquella en la que pronto se situaría Leibniz" (Joly, 1901: 66).

Cyril Morana comenta también la polémica de Malebranche con Arnauld, así como las relaciones irregulares con Bossuet. Para Morana, no obstante, la polémica se aviva unos pocos años antes con el padre Arnauld; en concreto, en 1677, con motivo de la publicación de Petites méditations sur l'humilité et la pénitence, fecha que estima el "arranque de la polémica" con relación al concepto de gracia "que conocerá su paroxismo en 1680 con el Traité de la nature et de la grâce" (Morana, 2006: 2). Cyril Morana recuerda también 
el modo en que Bossuet se desmarca del sistema de Malebranche y cómo el filósofo francés termina hastiado de tantas querellas con Arnauld y desencuentros con Bossuet:

Los ataques contra Malebranche no cesan de multiplicarse y Arnauld convence a Roma en 1690 para que incluya su obra en el Índice. Harto de polémicas de las que nunca ha sido partidario, firma en 1697 una obra de apaciguamiento, el Traité de l'amour de Dieu, que le reconcilia con Bossuet con relación a la cuestión del quietismo (Morana, 2006: 10).

En cualquier caso, todas estas controversias más o menos ásperas, más o menos alimentadas y continuadas de manera directa o indirecta a través de obras, artículos o relación epistolar, contribuyeron, una vez que llegaron a su fin, "a iniciar su apogeo en su reputación como mundano" (Joly, 1901: 37-38).

Syliane Malinowski-Charles recuerda que superaba a Descartes en "sostener la idea de que las sensaciones placenteras son buenas en sí mismas, lo que le provocó ser acusado de epicureísmo por Arnauld y Régis entre 1680 y 1690" (Malinowski-Charles, 2012: 74). En 1680 Arnauld criticaba en sus Reflexiones el hecho de que el placer sensible sea bueno. Bayle intervino en el debate tomando partido público en defensa de Malebranche en las Noticias de la República de las Letras en 1685, lo que dio lugar a un intercambio epistolar entre Bayle y Arnauld.

Arnauld respondió en 1687 con su Disertación sobre la supuesta felicidad de los sentidos, aún sin respuesta directa por parte de Malebranche. Cuando Régis publicó en 1690 su Sistema de Filosofía al abordar argumentos ya expuestos por Arnauld contra el placer (y contra la visión en Dios), Malebranche decidió tomar represalias, sospechando que era Arnauld quien se escondía detrás de la figura de Régis y quien lo manipuló. Luego publicó en 1693 una Respuesta a Régis incluida en todas las ediciones posteriores de la De la recherche de la vérité (MalinowskiCharles, 2012: 74). 


\section{§6. TEORÍA DEL ORDEN: EL OCASIONALISMO}

Toda la moral, epistemología y ontología del sistema de Malebranche confluye en lo que podemos llamar su teoría del orden. El orden no es sino Dios. $\mathrm{Y}$ el hombre no puede conocer los preceptos morales, no puede adquirir conocimiento verdadero si no escucha el Verbo divino. Nada existe si no es por el deseo del creador. La palabra orden recorre todas y cada una de las obras de Malebranche. Dios, además, no es solo garantía de conocimiento y existencia como lo era en los razonamientos de su admirado Descartes, sino que Dios es conocimiento. Todo aquello que no pase por oír su voz será aplicar una moral incorrecta, será conocimiento erróneo. Es por ello por lo que el hombre debe orientar su vida hacia el orden. Pero la brújula moral y epistemológica del ser humano, y ahí estriba la distinción de Malebranche en este periodo, parte de un mundo terrenal que no debe ser condenado. Eso sí, aunque rehabilita el mundo terrenal con sus placeres mundanos, pues forman parte de ese movimiento preambular hacia Dios, ha de ser correctamente dirigido en su linealidad hacia el orden: "Del mismo modo que para San Agustín, la razón habla a todos por igual pero en voz baja, restablecernos en el orden será pues dar la palabra a la Razón universal o Verbo divino" (De Buzon, 2014: 1184).

La teoría del orden es una reinterpretación de la teoría de las ideas de Platón, autor clásico en el que se inspira San Agustín para cristianizar su dualismo ontoepistemológico. No ha de sorprender al lector notar claros paralelismos de los textos del filósofo francés con los del pensador griego, dado que este último fue lectura del Padre de la Iglesia, pilar fundamental, a su vez, de Malebranche.

Su perspectiva se hace sistemática al constituir la teoría del orden, paralela a la modificación de la teoría de las ideas, asociada a la consideración de Jesucristo como causa ocasional, cuya razón de ser tiene como objetivo, al menos moralmente, conducir a los hombres a través de los sentidos a la Razón. En Traité de la nature et de la grâce, Méditation chrétiennes et métaphysiques y Traité de morale aparece, en las tres obras, un motivo recurrente, el del amor al orden, a través del cual Malebranche piensa en la caridad. No se trata ya solo de seguir las órdenes de Dios, tal como las expresó, sino de amar el orden que preside su prescripción (De Buzon, 2014: 1186). 
Malebranche dedica la primera página de su Traité de la morale al orden. En el capítulo I, centrado en las virtudes, con el que da comienzo la obra, el filósofo francés advierte al lector de lo siguiente: "La virtud o la perfección del hombre consiste en la sumisión al orden inmutable y de ninguna manera a seguir el orden de la naturaleza, error de algunos filósofos antiguos" (Malebranche, 1995: 59). Merecerá explicar y ampliar estas primeras oraciones. Y así lo hará. Pero ya se percibe también en ese final de frase su crítica a los filósofos antiguos, pues Malebranche apostaba por los viejos pensadores en temas de religión, pero por los nuevos pensadores en temas de filosofía, como iremos viendo a lo largo de este estudio. Es preciso escuchar a Dios, dado que así "podemos conocer el orden mediante la unión con el Verbo eterno, con la razón universal. Puede, así pues, ser nuestra ley, nos puede conducir", y es que el amor al orden "no es solo el principio de las virtudes morales, es la única virtud: es la virtud madre, fundamental y universal" y nada hay "más justo de conformarse al Orden. Nada hay más grande que obedecer a Dios" (Malebranche, 1995: 67-70).

Esta tendencia con unicidad de movimiento, sin interrupciones, progresiva y ascendente, Malebranche también la califica como natural a toda la humanidad. Su universalismo metafísico aparece en diversos pasajes, como cuando afirma que "se puede comenzar o dejar de amar a una criatura, pues el hombre no está hecho para dicha criatura, pero no se puede renunciar por entero a la razón, no se puede dejar de amar el orden; pues el hombre está hecho para vivir de la razón, para vivir según el orden. Así, el amor del orden reina naturalmente por doquier" (Malebranche, 1995: 88), haciendo hincapié en ese "naturalmente" y "por doquier", comentados antes de la cita. En Dios se halla la verdad, y solo Él es causa de conocimiento y moral: "Solo Dios expande la luz en los espíritus, verdad que ya he explicado, pero no se debe buscar más que en nosotros mismos la causa ocasional que le determina a comunicárnosla [...] el hombre ingrato y estúpido se torna vanidoso: se imagina ser la causa de sus conocimientos" (Malebranche, 1995: 104). En el apartado III del capítulo V, dedicado a la virtud, lo desarrolla más ampliamente:

Dios ha debido establecer en nosotros las causas ocasionales de nuestros conocimientos por buenas razones, siendo la principal de ellas que sin ello no fuéramos los amos de nuestra voluntad. Pues como nuestra voluntad 
debe ser iluminada para estimularse, si no estuviera en nuestro poder el pensar, no habría posibilidad de querer. No seríamos, pues, libres de una perfecta libertad, ni por consiguiente mereceríamos los verdaderos bienes de los que estamos hechos (Malebranche, 1995: 105).

Aunque no cita explícitamente el primer mandamiento del catecismo católico -el cual se inspira en la división que hace San Agustín de la lectura del Antiguo Testamento, del que se extrae el "Amarás a Dios sobre todas las cosas" del Éxodo y Deuteronomio-, lo vemos claramente en varias obras de Malebranche. Así, en el apartado XVI del capítulo VIII del Traité de morale afirma que el hombre debe amar a Dios "no solo más que la vida presente, sino más que a sí mismo", pues "así lo quiere el Orden” (Malebranche, 1995: 153). Y al carácter universalista de ese deseo de amor por Dios, le suma ahora la voluntad de perfección que de igual modo forma parte de la naturaleza humana.

El hombre no puede ser estimulado hacia este amor más que a través del amor natural e invencible que tiene por la felicidad y la perfección de su ser. El hombre no puede encontrar en sí mismo su felicidad y su perfección. Solo puede hallarlo en Dios, puesto que Dios es el único capaz de actuar en el hombre y de darle felicidad y volverlo perfecto. Nada vale nada más que estar con Dios (Malebranche, 1995: 153).

Dicho deseo antropológico de perfección, además, también aparece en la Biblia. Y Malebranche no vacila en citar, nuevamente, uno de los pasajes en los que se demanda a todo cristiano que sea perfecto. En el capítulo II del libro II de su Traité de morale, dedicado a los deberes, escribe: "Sed perfectos, decía Jesucristo a sus discípulos, como vuestro Padre celeste es perfecto" (Malebranche, 1995: 215), aludiendo a Mateo, 5.48: "Sed, pues, vosotros perfectos, como vuestro Padre que está en los cielos es perfecto".

Cuando el hombre escucha el Verbo divino se aleja de los placeres terrenales, esos que Malebranche califica de "ligeros", y se aproxima a los placeres "sólidos”. Llama la atención el uso de este adjetivo, no sabemos si por influencia cartesiana, o meramente debido al racionalismo y al peso científico de la época. 
Así, cuando explica la dualidad de placeres, se sirve de un campo léxico que remite a la física y que orbita, en concreto, al tipo de masa o densidad de estos:

Sin embargo, como queremos ser sólidamente felices, podemos sacrificar una parte de los falsos placeres, aunque presentes, en pos de sólidos placeres venideros $[\ldots]$ el placer actual no es siempre el amo del corazón. La experiencia nos enseña esta verdad, pues a menudo abandonamos placeres ligeros cuando poseemos la esperanza de adquirir otros más sólidos (Malebranche, 1995: 133).

Asistimos a una suerte de métrica cristianizada de los placeres del Jardín. Epicuro, muchos siglos atrás, también afirmaba que en ocasiones conviene renunciar a placeres actuales, o incluso sufrir dolor, en pos de un placer superior: "Hay veces que renunciamos a muchos gozos cuando de estos se derivan para nosotros más dolores que gozos, y hay veces que consideramos muchos dolores mejores que los gozos, concretamente cuando tras haber soportado durante mucho tiempo los dolores nos sigue un gozo mayor" (Epicuro, 2018: 90). En el último capítulo del libro II del Traité de morale, dedicado a los deberes, reaparecen dichos términos: "A nuestra felicidad, que consiste solamente en el gozo de los placeres, los entiendo como sólidos placeres y capaces de contentar un espíritu hecho para poseer el bien soberano" (Malebranche, 1995: 341).

Cuando el hombre no se repliega en sí mismo para escuchar el Verbo divino, cuando el ruido de los sentidos y la imaginación le ensordece, cae en la concupiscencia, como ya hemos explicado anteriormente. Y también en la vanidad. Alimenta su amor propio. Pero este puede ser reconducido con buenos hábitos para conducirlo al orden. En el análisis de Henry Joly sobre la figura de Malebranche se pone el acento en ese "consentimiento", pieza angular del pensamiento del filósofo francés: "Sea cual sea la acción natural o sobrenatural que Dios ejerce sobre nosotros, podemos siempre rechazar o afirmar nuestra adhesión a ella [...] podemos, y debemos decir, que cooperamos a su acción y así nos mantenemos dueños de nosotros mismos" (Joly, 1901: 140). A este respecto añade algunas páginas más adelante: "Esta luz no nos viene sin que la pidamos o busquemos; nos ilumina si la deseamos intensamente, sinceramente, valientemente. La parte de la voluntad libre en la creencia es 
considerable [...] ya que consentimos en adherirnos" (Joly, 1901: 144). Así lo ve también Jean-Luc Solère cuando hace hincapié en la necesidad de ese orden que guíe e ilumine al ser humano, una luz cuya energía pasa por un movimiento de humildad en el ser humano:

Para mejor exaltar la gracia no merecida, el don gratuito, rebajamos al hombre. Y es rebajar la superioridad del hombre el hecho de mostrarle que en verdad no busca más que su placer, es decir, que es incapaz por sí solo de una acción verdaderamente virtuosa, incapaz de desear un bien que fuera honesto sin ser útil ni agradable (Solère, 1995: 355).

Mariangela Priarolo, no obstante, no duda en poner el acento en el "antihumanismo" que se desprende de la teoría ocasionalista de Malebranche. El recurso de Malebranche al ocasionalismo, a saber, la tesis según la cual solo Dios es la causa real y que, por consiguiente, es a Él solo a quien se debe amar por los placeres que recibimos del mundo, suscitaría un antihumanismo que consistiría en la "limitación radical" del espacio reservado a la libertad y la razón del hombre: "En efecto, la filosofía de Malebranche, en particular su teoría del conocimiento, y su visión de las ideas en Dios, no parece conferir gran valor a las capacidades humanas" (Priarolo, 2015: 150). La visión positiva de la naturaleza humana, vista en algunos pensadores malebranchistas como Abbadie, será duramente criticada por François Lamy, quien toma del agustinismo (y del jansenismo) la tesis de que el amor de sí, en tanto que amor propio, es la fuente de todos los pecados: "La autoridad sobre la que Lamy escoge apoyar su crítica no es San Agustín, sino un viejo amigo que se había inspirado a su vez en San Agustín para levantar buena parte de su filosofía: Nicolas Malebranche" (Priarolo, 2015: 153).

Bardout añade en relación al ocasionalismo y al placer unido a la voluntad y libertad que Dios entra en relación con el yo afectado bajo la categoría de placer vivido: "Dios es así retomado como la causa universal e inmediata de todo placer, como es así la tesis central del ocasionalismo, según la cual es la única causa eficiente, así pues, la única causa real del placer [...] el placer no debe ser buscado por él mismo, sino por el fin hacia el que nos dirige y que nos hace conocer en cierto modo" (Bardout, 2005: 107-108). 
Para acabar este apartado, conviene recordar que Malebranche-como Bayle- separa radicalmente el alma del cuerpo. No existe placer físico sentido en el cuerpo, ya que nada psíquico se halla en la materia: "El cuerpo no actúa en el alma para hacerle sentir placer: es Dios quien directamente causa en nuestra alma una sensación «a la ocasión» de ciertas modificaciones materiales que intervienen en nuestro cuerpo" (Solère, 1995: 365).

\section{§7. SI NO HAY ORDEN, HAY AMOR PROPIO}

Hemos visto cómo Malebranche cita la Biblia para manifestar la voluntad de perfección que debe acompañar, por precepto cristiano, la ética del individuo (Mateo, 5.48). Ese imperativo de mejora cristiana se plasma en el concepto de amor propio, tan estudiado a lo largo de los siglos XVII y XVIII. Desde Pascal y La Rochefoucauld hasta Hume, la lista resulta inabordable. El amor propio como voluntad de mejora, en tanto en cuanto se debe aspirar a Dios, forma parte de la naturaleza humana. Malebranche nos dice, pues, que no podemos contener esas aguas de perfección que recorren nuestro interior, esa energía espiritual -o "energía vital”, como la llamará Nietzsche-. La importancia metafísica estriba en que dicho torrente ha de canalizarse al orden. Bien guiado, el amor propio de hombre le hará buen cristiano. Pero si el cristiano no escucha el Verbo divino su amor propio le hará vanidoso, egoísta y concupiscente, pues se quedará anclado en unos deseos terrenales y no terminará de desenvolverse esa dinámica lineal del alma de la que hablamos al principio de este estudio.

En su Traité de moral Malebranche desglosa una lista de deberes, que recorreremos más adelante, a los que todo buen cristiano debe seguir a fin de que su amor propio no se vea corrompido. La antropología metafísica, como hemos explicado, no puede detenerse. Ahora bien, sí que está en nuestra mano dar (o no) el consentimiento al mal camino. "El principio de toda conducta moral es el amor propio que no libera al hombre de querer su felicidad. Pero si uno no puede dejar de quererse, sí que puede dejar de mal quererse" (Mauzi, 1994: 636).

Basta con que el amor propio, recibiendo algunas luces de la fe, renuncie a placeres inmediatos y mediocres, en pos del absoluto de una felicidad lejana. 
Esta elección no supone ninguna gran intervención sobrenatural. Es un mecanismo de la naturaleza, que no solo es la que lo inspira, sino que saca provecho de ello, pues la gracia no destruye la naturaleza. El amor propio no es el peso de la carne, que precipita al hombre de caída en caída, es la inercia del alma que desea conquistar el verdadero bien y que, por desprecio o pereza, se retrasa en males accidentales o falsos (Mauzi, 1994: 636).

Reconocer el orden, fundamento de la virtud, implica el descubrimiento del sentimiento interior. Ese repliegue hacia nuestro propio interior agustiniano se opone a la concupiscencia que distrae la atención hacia el exterior, hacia los sentidos y lo imaginario. Hemos visto que Malebranche, merced a una curiosa teoría fisiológica del cuerpo humano, justifica en las mujeres y en los hombres de cierta edad una predisposición a lo exterior. El prestar más atención al exterior que al interior, por motivos fisiológicos -la sensibilidad de las "fibras" del cerebro-, tiene como consecuencia un amor propio que no logra recibir la luz divina y cae en el error. Durante todo el libro II de De la recherche de la vérité, los ejemplos de esta vía del error son múltiples. $\mathrm{Su}$ crítica se cierne con mayor virulencia entre los eruditos y estudiosos de otros autores, que no hacen más que pecar de vanidad:

Se imaginan que los autores que comentan merecen la admiración del resto de la humanidad. Se miran a sí mismos como si se vieran con dichos autores siendo una misma persona: y en esta visión el amor propio juega admirablemente su juego. Dan con admirable destreza loas a sus autores, los inundan de gloria, sabiendo bien que dicha gloria revertirá en ellos mismos (Malebranche, 1842: 161).

Malebranche, como buen teólogo, destila pasajes del Eclesiastés en su crítica a la vanidad del ser humano que se cree conocedor de cuanto le rodea, de las causas que le mueven, cuando no es sino un ignorante. Esto se percibe cuando sentencia, con relación a los inventores de nuevos sistemas: "Y por qué tienen tanta dificultad para decir: no sé nada [...] y se debe concluir que todos los hombres son ignorantes" (Malebranche, 1842: 169).

Pero lo importante aquí, como bien señalaba Mauzi en su análisis de Malebranche, es que la gracia no destruye la naturaleza. El filósofo francés reconoce la imposibilidad de una reducción a la inteligibilidad pura: el hombre es 
carnal y se debe, pues, utilizar este aspecto esencial de su naturaleza poniéndolo al servicio del orden, pues de no hacerlo el amor propio permanecería envuelto de exterioridad y concupiscencia. El pastor Jacques Abbadie publicó en 1692 L'art de se connaître soi-même ou la Recherche de sources de la morale con la intención de resolver esta contradicción del amor propio que acabamos de señalar y que Malebranche neutraliza con su listado de deberes en su Traité de morale. Abbadie, teólogo protestante emigrado a Brandenburgo algunos años de la promulgación del Edicto de Fontainebleau, oponía a la visión jansenista del hombre una moral que retomaba del epicureísmo la centralidad del placer y del deseo de felicidad en la vida humana.

Los últimos párrafos del libro II de su Traité de morale se presentan como una firme voluntad de acabar la obra, remarcando qué es el amor propio y cuáles son los deberes del buen cristiano para alejarlo de la concupiscencia: "El amor propio, por decirlo con exactitud, no es una cualidad que pueda aumentarse o disminuirse: uno no puede dejar de amarse, pero uno puede dejar de mal amarse. No puede detenerse el movimiento del amor propio, pero lo podemos vehicular bajo la ley divina" (Mauzi, 1994: 342). Y unas líneas más adelante, añade:

Nuestro amor propio es, pues, el motivo que, socorrido por la gracia nos une a Dios, como a nuestro bien o la causa de nuestra felicidad; y nos somete a la razón, como a nuestra ley, o al modelo de nuestra perfección. Pero no debemos hacer nuestro fin, o nuestra ley, de nuestro motivo, debemos verdadera y sinceramente amar el Orden y unirnos a Dios mediante la razón. Debemos preferir la ley divina sobre todas las cosas (Mauzi, 1994: 343).

En estas líneas vemos nuevamente el primer mandamiento del catecismo católico. Incluso uno parece escuchar el Non nobis, Domine, non nobis, sed nomini tuo da gloriam ("No a nosotros, Señor, no a nosotros, sino a Tu nombre, da la gloria"), lema de la orden templaria. Pero para dirigirnos a Dios debemos escuchar su voz. Él nos habla en voz baja: “Como para San Agustín, la razón habla a todos por igual, pero en voz baja, restablecernos en el Orden supondrá dar la voz al Verbo divino [...] solo Dios es digno de amor sin remordimientos, dado que se trata del bien infinito; para cualquier otro tipo de 
amor esta unión divina padece una pausa ilegítima del movimiento natural depositado en el alma" (De Buzon, 2014: 1184-1185).

De gran interés resulta el amor propio, o la búsqueda de placer, como motivo de todo movimiento del hombre. El amor propio como causa intencional de toda acción humana: "El placer, como el deseo de ser feliz o el amor propio, constituyen el motivo físico de toda acción, pero el hombre debe buscar a Dios para conducirlo hacia su verdadero fin" (De Buzon, 2014: 1188). Esta idea influencia autores contemporáneos, pero esto se abordará en la parte final de este estudio, donde se hará referencia también a la obra de Albert O. Hirschman Las pasiones y los intereses.

San Agustín distingue el amor propio y la auténtica caridad, que no es sino el amor de Dios, pero también de las otras criaturas en tanto que criaturas de Dios. Dirigiéndonos hacia Dios, me dirijo hacia los otros hombres, en ese movimiento de gracia que es el proceso imitativo de Dios, querido por Él, y que posibilita lo cívico y la unión social. Malebranche da una vertiente metafísica a la sociabilidad humana, al carácter político del individuo que siglos antes había señalado Aristóteles. Con el filósofo griego, no obstante, tuvo Malebranche encuentros y desencuentros dignos de estudio.

Malebranche es heredero de la ambición fundadora de la metafísica con respecto a la ética. El filósofo francés insistía en que es la buena metafísica la que debe regular todo: "La moral de Malebranche depende estrechamente de su situación metafísica, hasta para confiar a esta 'ciencia general' la misión de procurarle su primer principio [...] por decirlo de otro modo, si corresponde a las ciencias particulares determinar la naturaleza de su objeto, corresponde a la metafísica asegurar a esas mismas ciencias toda su certeza" (Bardout, 2005: 97).

\section{$\S 8$. Conclusión}

Malebranche representa una figura clave en la rehabilitación del concepto de placer en este difícil tránsito que supone la condena de lo mundano en el siglo XVII y la dotación de un valor positivo de la figura del hombre en el Siglo de las Luces. El filósofo y teólogo francés, además, se alza como uno de esos 
pensadores que suavizan la moral cristiana desde el seno de la cristiandad, lo que le supuso graves enfrentamientos con casi todos los ángulos religiosos de la época: desde el padre Arnauld (y el jansenismo de Port Royal) hasta Fénelon (y el quietismo de Miguel de Molinos), pasando por los jesuitas y la escolástica, y el propio Bossuet. Con ninguno de ellos, sin embargo, deseó entablar polémica.

Vivió Malebranche como un hombre tranquilo, hogareño e intenso lector, cuyo recorrido vital le hizo muy devoto de San Agustín. La metafísica no solo impregna la obra de Malebranche, sino que cimienta toda su filosofía. Y la religión, como él dice, es la única filosofía. Una filosofía que tiende al orden. Quien no se repliega hacia su interior no conocerá el orden. El hombre tiene la capacidad de hacerlo si consiente a ello. Está en sus manos. Como buen cartesiano defiende las posibilidades cognitivas del yo, pero le añade la capacidad volitiva para dotarlo de libertad. Un ser humano que es capaz, eso sí, pero no autosuficiente como pretendía su admirado Descartes. Dios no es solo garante epistemológico; es creador y causa de todo. Ha depositado en el hombre un impulso que provoca su ascensión gradual y natural hacia la verdad que solo Dios conoce y de la que, de manera ocasional, permite participar al hombre de vida ordenada.

Cohabitar en la sordidez social pertenece a la antropología. Es irrenunciable la ética política aristotélica. En esta tragedia que supone el "sacrificio continuo" de lo mundano se debate el hombre desde que nace. Dios susurra la verdad al hombre y debemos mortificar los sentidos para minimizar el ruido mundano y escapar de la concupiscencia. Pero esta mortificación no significa eliminación corporal ni abandono social, sino redirección al orden. La directriz metafísica reconoce lo mundano, pues el impulso que Dios ha depositado en el hombre metafísico debe arrancar en dichos placeres terrenales. Será a partir de ellos que la humanidad se reconciliará con ella misma y logrará escuchar la verdad del único que sabe la causa de todo cuanto acontece, del único creador de todo cuanto sucede. Entre los demás, a partir de lo mundano, si el hombre escucha y consiente, será feliz. Uno no puede dejar de amarse, reconocerá Malebranche, pero uno puede dejar de mal amarse, puntualizará. Este amor propio como causa intencional de toda acción humana, que deberá orientarse al orden en su pensamiento, influenciará multitud de autores venideros. 
Insistiendo, como lo hace, en la necesidad del hombre de merecer la gracia, Malebranche podría coquetear con las tesis de Pelagio. En su sistema, como lo recuerda Vicent Gary, "corresponde al hombre actuar para prepararse" (Geny, 2015: 502). No obstante, el oscurecimiento del conocimiento de sí mismo que tiene el hombre le empuja a una imposibilidad de certezas sobre su futuro: "La pregunta de si he merecido lo suficiente para obligar a Dios a salvarme no hallará respuesta más que al fin de nuestra existencia" (Geny, 2015: 504).

En definitiva, Malebranche dota de actividad al sujeto, pero sin hacerlo todopoderoso. Rehabilita el placer mundano en la ascensión metafísica de un Dios que ya no es solo garante, sino que es causa de todo, moral incluida, y por el que el individuo debe crear en la tragedia mundana la "ocasión favorable" para poder escuchar su voz. Para ser feliz.

REFERENCIAS BIBLIOGRÁFICAS

Agustín, S. (2010). La ciudad de Dios. Madrid: Tecnos.

Bardout, J.-C. (2005). Malebranche et la situation métaphysique de la morale. Presses Universitaires de France (17è siècle), 95-109.

Canto-Sperber, M. (2014). Dictionnaire d'éthique et de philosophie morale. París: PUF.

Chaponnière, P. (1922). Revue d'histoire littéraire de la France.

Darmond, J. C. (1998). Philosophie épicurienne et littérature au 17ème. París: PUF.

De Buzon, F. E.-S. (2014). Dictionnaire d'éthique et de philosophie morale. París: PUF.

Descartes, R. (1996). Les passions de l'âme. París: Flammarion.

Descartes, R. (2010). Discurso del método. Madrid: Espasa-Calpe.

D'Hautefeuille (1969). Malebranche ou la prière cartésienne. Reuve de métaphysique et de morale, 472.

Epicuro (2018). Obras completas. Madrid: Cátedra. 
Garmendia de Camusso, G. (2004). Experiencia y filosofía: de la finitud a la eternidad. Buenos Aires: Colihue.

Geny, V. (2015). Le plaisir et la grâce chez Malebranche. Presses Universitaires de France, 491-504.

Gueroult, M. (1954). Métaphysique et physique de la force chez Descartes et chez Malebranche. Revue de métaphysique et de morale, 113-134.

Gueroult, M. (1959). Malebranche. París: Aubier-Montaigne.

Israel, J. (2012). La Ilustración radical. Madrid: FCE.

Jolley, N. (2002). Occasionalism and Efficacious Laws in Malebranche. Midwest Studies in Philosophy (26), 245-257.

Joly, H. (1901). Malebranche. París: Félix Alcan.

Long, A. (1994). La filosofía helenística. Madrid: Alianza Universidad.

Lovejoy, A. O. (1923). Representative Ideas in Malebranche and Arnauld. Oxford University Press, 449-461.

Malebranche, N. (1842). De la recherche de la vérité. París: Wikisource (Texte étable par Jules Simon Charpentier).

Malebranche, N. (1995). Traité de morale. París: Flammarion.

Malinowski-Charles, S. (2012). Les passions chez Malebranche et Lamy ou ce que la théorie des passions de Malebranche doit à son occasionalisme. En L. E. Desjardins, Penser les passions à l'âge classique (pp. 67-86). París: Hermann.

Marmontel, J. F. (1757). La Enciclopedia (vol. VII). París: Enccre (en línea).

Mauzi, R. (1994). L'idée du bonheur dans la littérature et la pensée françaises au xviiie siècle. París: Albin Michel.

Montaigne, M. (2002). Essais. París: Arléa.

Montesquieu (2014). Mes pensées. París: Gallimard.

Morana, C. (2006). De la recherche de la vérité, livre II, parties II et III. París: Bréal.

Nicole, P. (1671). Essais de morale. París: Les Belles Lettres, collection "Encre Marine" (2016).

Pascal, B. (2000). Pensées. París: LGF. 
Priarolo, M. (2015). Un plaisir divin: Malebranche, Lamy (et les autres). Le malebranchisme à l'épreuve de ses amis et de ses ennemis (pp. 149-168). París: Honoré Champion.

Schmaltz, T. (2008). Occasionalism and mechanism: Fontenelle's objections to Malebranche. British Journal for the History of Philosophy, 298-313.

Solère, J.-L. (1995). Tout plaisir rend-il heureux? Une querelle entre Arnauld, Malebranche et Bayle. Chroniques de Port-Royal (vol 44), 351-379.

Vidal-Benyeto, J. (2006, 2 de septiembre). El culto de la cultura. El País.

Voltaire (1878). Le Siècle de Louis XIV. París: Édition Garnier. 